\title{
Optimal and judicious blood transfusion usage - a mandate to save maternal lives
}

\author{
Surekha Atul Tayade, Pranali Thool, Nitin Gangane, Jaya Kore, Neha Gangane \\ Correspondence: Dr Surekha Atul Tayade, Professor, Obstetrics and Gynecology, Mahatma \\ Gandhi Institute of Medical Sciences, Sewagram, India; Email - stayade@mgims.ac.in
}

Distributed under Attribution-NonCommercial-ShareAlike 4.0 International (CC BY-NC-SA 4.0)

\begin{abstract}
Objectives: This study was carried out to see the incidence and indications of transfusion of blood and blood components in obstetrics at a tertiary care hospital. Material and Methods: Hospital information system was used to identify obstetric patients requiring blood transfusion over a period of one year and data were analyzed to determine the incidence and indications for blood transfusion. Results: Of the total blood transfusion requirements in the hospital, $13.52 \%$ were for obstetric patients. Overall, $6.13 \%$ of obstetric admissions required blood/component transfusion. Severe anaemia (38.88\%), accidental haemorrhage (11.11\%), postpartum haemorrhage (14.31\%), placenta previa $(6.19 \%)$ and caesarean section $(8.76 \%)$ were the common indications for blood transfusion. Component transfusion was needed in $81.32 \%$. Two or more units of transfusion were needed in $86.97 \%$ women and massive transfusion was required in $13.24 \%$. Conclusion: In the present study, availability of blood and components were seen to be the main determinant which contributed in saving maternal lives. The main indications of blood transfusion was severe anemia and obstetric haemorrhage of various forms and etiology were the other common indications. Not only whole blood but component transfusion was instrumental in correcting specific deficiency.
\end{abstract}

Keywords: Blood transfusion, maternal lives, optimal use, life saving.

Though pregnancy and childbirth is a physiological event and most births are uneventful, all pregnancies are at risk. Around $12-15 \%$ of all pregnant women develop a potentially life-threatening complication that calls for skilled care, and some will require a major obstetrical intervention to survive ${ }^{1}$. In India, Obstetric hemorrhage with varied presentations and etiology, still remains the direct cause of maternal mortality. Anemia is a major contributory factor and increases the morbidity manifold ${ }^{2}$. Emergency obstetric care (EmOC), access to family planning, and skilled attendance at birth are three key interventions that have been implemented globally to reduce maternal mortality. Safe and sufficient blood transfusion facility is an important component of comprehensive obstetric care and could help prevent deaths of a significant number of mothers and their newborn children.

Obstetric emergencies occur suddenly and unexpectedly. Common emergency indications for blood transfusion are haemorrhage in the first trimester due to

Received: $26^{\text {th }}$ April 2018. Accepted: $3^{\text {rd }}$ September 2018.

Tayade SA, Thool P, Gangane N, Kore J, Gangane N. Optimal and judicious blood transfusion usage - a mandate to save maternal lives. The New Indian Journal of OBGYN. 2019; 5(2): 83-7 
abortions, ruptured ectopic pregnancies or molar pregnancies, bleeding in later pregnancy due to placenta previa or placental abruption, third stage complications like postpartum haemorrhage, retained placenta or acute inversion of uterus. Some patients of severe anaemia nearing term, liver disease or chronic kidney disease on dialysis, hemophilia require blood transfusion. In central India hemoglobinopathies like sickle cell disease and thalassemia also form a major indication for blood transfusion. Operative blood loss during caesarean section, laparotomy for rupture uterus or placenta accreta and evacuation for incomplete abortion or vesicular mole are also significant indications for emergency blood transfusions ${ }^{3}$.

Ensuring a safe supply of blood and blood products and the appropriate and rational clinical use of blood are important public-health responsibilities of every national and state government, especially for saving lives of mothers who need comprehensive emergency obstetric care services ${ }^{4}$. However, transfusion facilities are limited and carry a small but significant risk of complications and allergic/anaphylactic reactions. Appropriate and judicious use is obligatory and clinicians should be aware of the appropriate guidelines. Thus this study was carried out to study the incidence and indications of transfusion of blood and blood components in Obstetrics at a tertiary care hospital and recommend good practices for saving maternal lives.

\section{Methods}

This was a retrospective cross sectional analytical study carried out in the Kasturba Hospital of rural central, India from January 2017 to December 2017. This hospital is attached to MGIMS, Sevagram which is a tertiary care rural institute situated in eastern Maharashtra. All the data of patients is entered in Hospital Information System (HIS) since 2007 and the system is completely paperless. In the present study, data regarding number of blood units transfused and the indications for transfusion were collected from all maternity wards, operation theatre, labour room and HDU /ICU from January 2017 to December 2017. Hospital information system was used for data acquisition and analysis was done.

\section{Results}

In the present study retrospective analysis of utilization of blood and component transfusion facilities
Table 1: Maternity services in Maternal and Child Health Wing (2017)

\begin{tabular}{ll}
\hline Categories & Number \\
\hline Obstetric admissions & 7631 \\
Total deliveries & 5363 \\
Caesarean sections & 1823 \\
Abortion Services availed & 392 \\
Admissions in HDU /CU & 755 \\
$\begin{array}{l}\text { No. of Patients requiring blood transfusion } \\
\text { Percentage of Obstetric admissions requiring } \\
\text { blood transfusion }\end{array}$ & 468 \\
\hline
\end{tabular}

by MCH wing of Kasturba Hospital, MGIMS Sevagram over a period of one year was done. During the study period, there were 7631 obstetric admissions and 5363 deliveries, including 1823 caesarean sections. Comprehensive abortion services were availed by 329 women including medical terminations. Total 468 patients (6.13\%) required blood and component transfusion. During the period of study, there were 755 admissions in Obstetric HDU and ICU amounting to $9.89 \%$ of total 7631 obstetric admissions (Table 1). Out of the total, 4605 blood units issued from the hospital blood bank to all departments, $623(13.52 \%)$ were issued to the maternity unit for obstetric patients (Table 2). This included 20.06 $\%$ of whole blood and remaining $79.94 \%$ of component transfusion. Use of packed cells was limited to $8.50 \%$, fresh frozen plasma was used in $39.32 \%$ and platelet

Table 2: Blood and components usage in the hospital

\begin{tabular}{ll}
\hline Department & $\begin{array}{l}\text { Total no of Blood/ } \\
\text { Components issued }\end{array}$ \\
\hline All Departments & 4605 \\
$\begin{array}{l}\text { Obstetrics } \\
\% \text { of Blood Units issued to }\end{array}$ & 623 \\
Obstetrics & $13.52 \%$ \\
\hline
\end{tabular}

transfusion was in $32.10 \%$ (Table 3). Cryoprecipitate was not utilized for maternity patients. Two or more units of transfusion were needed in $86.97 \%$ women and massive transfusion was required in $13.24 \%$ (Table 4). Most common indications of use was severe anemia $(38.88 \%)$, followed by postpartum hemorrhage (14.31\%) and placental abruption (11.11\%). Other common indications were Placenta previa $(6.19 \%)$, ruptured ectopic pregnancy $(3.84 \%)$ and sickle cell disease $(2.56 \%)$. Less common indications were abortions, rupture uterus, 
Table 3: Blood and components usage in Mother and Child Wing

\begin{tabular}{ll}
\hline $\begin{array}{l}\text { Type of blood and } \\
\text { components }\end{array}$ & $\begin{array}{l}\text { No of units transfused }(\mathbf{N}=623) \\
\text { Percentage }\end{array}$ \\
\hline Whole blood & $125(20.08 \%)$ \\
Packed cell volume & $53(8.50 \%)$ \\
Fresh frozen plasma & $245(39.32 \%)$ \\
Platelets & $200(32.10 \%)$ \\
\hline
\end{tabular}

Table 4: Requirement of Blood transfusions per case

\begin{tabular}{ll}
\hline $\begin{array}{l}\text { No. of blood Units } \\
\text { transfused per case }\end{array}$ & $\begin{array}{l}\text { Total No. of Cases }(\mathbf{N}=468) \\
\text { Percentage }\end{array}$ \\
\hline 1 & $61(13.03 \%)$ \\
2 & $185(39.52 \%)$ \\
3 & $98(20.95 \%)$ \\
4 & $56(11.96 \%)$ \\
5 and more & $62(13.24 \%)$ \\
\hline
\end{tabular}

Table 5: Indications of Blood transfusion usage

\begin{tabular}{ll}
\hline Indications & No (\%) \\
\hline Postpartum Haemorrhage & $67(14.31 \%)$ \\
Severe anemia in pregnancy/ postpartum & $182(38.88 \%)$ \\
Placenta Previa & $29(6.19 \%)$ \\
Abortions & $12(2.56 \%)$ \\
Ectopic pregnancies & $18(3.84 \%)$ \\
Vesicular mole & $7(1.49 \%)$ \\
Rupture Uterus & $5(1.06 \%)$ \\
Caesarean Section & $41(8.76 \%)$ \\
Placental Abruption & $52(11.11 \%)$ \\
Obstetric hysterectomy & $7(1.49 \%)$ \\
Retained placenta/ Inversion of Uterus & $5(1.06 \%)$ \\
Acute or chronic liver and kidney diseases & $8(1.23 \%)$ \\
Sickle Cell disease & $12(2.56 \%)$ \\
Others & $23(4.91 \%)$ \\
\hline
\end{tabular}

vesicular molar pregnancy and retained placenta, inversion of uterus, etc. (Table 5)

\section{Discussion}

Kasturba hospital is a 1000 bedded health care facility catering to rural masses and has a dedicated state of art Mother and Child Health Wing. The Maharashtra state has a maternal mortality ratio of 68 per one lakh live births (SRS 2011-13) and the health system is striving hard to provide quality maternity care and reduce maternal mortality further. The Department of Obstetrics and Gynaecology (OBGY) believes in providing quality services with a human touch to all the rural and urban women visiting the outdoor and indoor sections. The department have facilities for antenatal, postnatal, gynecological care as well as critical care, caters to around 5000 deliveries per year and has adopted 56 surrounding villages for providing community reproductive health. The $\mathrm{MCH}$ wing providing comprehensive obstetric services receives referral of high risk maternity cases and morbidly ill women from neighbouring districts of Maharashtra as well as neighbouring states of Andhra Pradesh and Madhya Pradesh.

Complications of pregnancy and childbirth associated with the need for blood transfusion may lead to morbidity and mortality if not managed correctly and in a timely manner ${ }^{5}$. These include obstetric hemorrhage, operative interventions, labour complications and severe anemia with its associated co morbidities. Obstetric haemorrhage remains a major cause of maternal mortality in India and is the leading cause of direct maternal deaths. Globally about $11 \%$ of women have severe PPH amounting to 14 million women a year ${ }^{6}$. In India alone postpartum hemorrhage accounts for nearly $38 \%$ of all maternal deaths ${ }^{7}$. Substandard management continues to be a significant contributor to mortality from haemorrhage. Retrospective analyses of the clinical scenarios often criticize the employment of blood transfusion as 'too little, too late' ${ }^{5}$. Women at high risk of losing greater than $1000 \mathrm{ml}$ should be strongly advised to deliver in a setting where blood transfusion and intensive care facilities are available.

Pregnancy although a physiological state, can turn pathological, suddenly and unexpectedly, if not cared for. Immediate \& rapid replacement of loss with sufficient and safe blood becomes essential to save maternal lives. No other fluid can replace blood as efficiently, hence the importance of blood bank services in Obstetrics. No maternity hospital is safe for confinement unless supported by blood bank facility ${ }^{3}$.

Most of the donated blood is processed into components: packed red cells (PRBCs), platelets, and fresh frozen plasma (FFP) or cryoprecipitate. Various alternatives to blood transfusion exist and include autotransfusion, pre-autologous blood storage, use of oxygen carrying blood substitutes and intraoperative cell salvage. Despite the risks associated with transfusions, obstetricians are frequently too aggressive in transfusing blood and blood products to their patients ${ }^{8}$.Blood transfusion though a life-saving procedure is not without 
risk. Recipients may rarely develop transfusion related complications like anaphylaxis and infections and fatal red cell allo-immunisation. The major risk, however, of blood transfusion is of a patient receiving an 'incorrect blood component'. Hence, blood transfusion policy and protocol is of paramount importance?

In India, the numbers of blood banks are meagre as compared to the developed countries. Due to difficult terrains and geographical features many a times blood banks are not within reach of hospitals catering to maternity services. The problems are severe in rural and even worse in tribal regions. The blood stock is often insufficient and does not assure the availability of blood in all dire emergencies ${ }^{3}$. Even more so is the scarcity of components like fresh frozen plasma and platelets. The treating clinician has to anticipate the need for transfusion and make necessary arrangements well in advance. Failure to anticipate can result into disaster ${ }^{10}$.

Prevention being better than cure, antenatal risk assessment and evaluation of hemoglobin status is essential. Dietary advice regarding consumption of iron rich substances and prophylactic iron therapy, help in maintaining normal hemoglobin level ${ }^{11}$. For normocytic or microcytic anaemia, a trial of oral iron should be considered as the first step and further tests should be undertaken if there is no demonstrable rise in $\mathrm{Hb}$ at the end of 2 weeks and compliance has been checked. Pregnant women should be offered screening for anaemia at booking and at 28 weeks. Women with multiple pregnancies should have an additional full blood count done at 20-24 weeks. Oral iron should be the preferred first-line treatment for iron deficiency. Parenteral iron is indicated only when oral iron is not tolerated or absorbed or patient compliance is in doubt or if the woman is approaching term and there is insufficient time for oral supplementation to be effective. Active management of the third stage of labour is recommended to minimize blood loss. Women at high risk of haemorrhage should be advised to deliver in hospital. Whole blood transfusion should be spared for severe anaemia with cardio respiratory symptoms, where packed cell volume should be preferred over whole blood to avoid volume overload ${ }^{5}$. Anaemia not due to hematinic deficiency (for example, haemoglobinopathies or bone marrow failure syndromes) should be managed by blood transfusion where appropriate in close conjunction with a hematologist.

There should be a clear local protocol on how to manage major obstetric haemorrhage. The protocol should be updated annually and practiced in 'skills drills' to inform and train relevant personnel. Clinicians should be familiarized themselves with mechanical strategies that can be employed to reduce postpartum blood loss. There are no firm criteria for initiating red cell transfusion. The decision to perform blood transfusion should be made on both clinical and hematological grounds.

Fresh frozen plasma is very useful in the management of accidental haemorrhage and cases with massive blood loss. It prevents or controls dreadful complication like disseminated intravascular coagulation. Severe variety of abruption may demand multiple units of fresh frozen plasma $^{3}$. The platelet count should not be allowed to fall below $50 \times 10^{9} / 1$ in an acutely bleeding patient as this represents the critical level for hemostasis. A platelet transfusion trigger of $75 \times 10^{9} / 1$ is recommended in a patient with ongoing bleeding, so as to provide a margin of safety. Platelets may not be on-site in many units; therefore their need should be anticipated and good communication with the transfusion laboratory maintained.

The use of a Patient Blood Management (PBM) program is recommended by American Association of Blood Banks. PBM involves an all-encompassing approach to avoid unnecessary transfusion by optimizing preoperative/predelivery $\mathrm{Hb}$, avoiding over transfusion, using cell salvage where appropriate, accepting evidencebased lower transfusion triggers and using intravenous or oral iron supplements in women who are not actively bleeding and are cardiovascularly stable ${ }^{12}$.

Invasive monitoring, ionotropic support, invasive ventilation are often accompaniments of massive blood transfusion. Blood banks must be informed in advance, if Obstetrician suspects the possible need of massive blood transfusion. Networking of blood banks helps in making blood available in short period of time. The relatives of the patients should be encouraged to donate blood.

\section{Conclusion}

Blood and component transfusion is the most essential entity of comprehensive obstetric care. Judicious and 
optimum use of blood is recommended in obstetric emergencies. Various obstetric emergencies are unpredictable, however antenatal risk assessment and correction of nutritional anemia gives a big advantage when real emergency strikes. A clear blood transfusion protocol is a mandatory in all obstetric units and should be well known to each health care provider of the unit. Blood transfusion audit is useful in maintaining the quality of health care services. Whole blood transfusions should be discouraged and replaced by packed cell and component transfusion in appropriate ratio . Anticipating the need for components well in advance and keeping the Blood bank informed is the key to saving maternal lives. Voluntary blood donation programmes should be strengthened and blood bank networking should be established.

\section{Acknowledgements}

We are grateful to the department of Obstetrics and Gynaecology and Department of Pathology, MGIMS, Sevagram and Hospital Information System, for helping us in conducting this study.

\section{Conflict of interest: None. Disclaimer: Nil.}

\section{References}

1.PATH. Comprehensive Emergency Obstetric Care. Technology Opportunity Assessment. In: (PATH) PfATiH, editor. Prepared for Mothers Program. Seattle: WA; 2013.

2.Patel VP, Patel RV, Shah PT, Patel CK. Study of role of blood transfusion in obstetric emergencies. 2017; 3(4): 4.

3.Bangal VB, Gavhane SP, Aher KH, Bhavsar DK, Verma PR, Gagare SD. Pattern of utilization of blood and blood components in obstetrics at tertiary care hospital. 2017; 6(10): 6 .

4.Chowdhury F, Akhter S, Islam A, Rayen J, Begum N, Begum F. Evaluation of Blood Transfusion Practices in
Obstetrics and Gynecology in a Tertiary Hospital in Bangladesh. 2016; 34(1):6.

5.RCOG. Blood Transfusion in Obstetrics. Green top Guidelines 47 In: Gyencologists RCoOa, editor. London, UK; 2015.

6.Parikh MN. Introduction of postpartum hemorrhage. Fogsifocus. 2007;1(2):3.

7.Registrar General of India. Sample registration survey. Maternal mortality in India: trends, causes and risk factors. In: Registrar General of India eAS, editor. New Delhi; 2006. p. 29.

8.Nigam A, Prakash A, Saxena P. Blood transfusion in obstetrics. Kathmandu University medical journal (KUMJ). 2013;11(44):355-9.

9.WHO. Essential health technologies. Blood transfusion safety. 2011.

10.Nuttall GA, Stehling LC, Beighley CM, Faust RJ. Current transfusion practices of members of the american society of anesthesiologists: a survey. Anesthesiology.

2003;99(6):1433-43.

11.Kawthalkar AKV, Joshi S, Bhalerao A, Kumare B, Somalwar S. Blood transfusion in Obstetrics and Gynaecology: A retrospective analysis. Panacea J Med Sci. 2015;5(3):109-12.

12.British Committee for Standards in Haematology BTTF. Guidelines for the clinical use of red cell transfusions. Br J Haematol. 2001;113:24-31.

\footnotetext{
Surekha Atul Tayade ${ }^{1}$, Pranali Thool ${ }^{2}$, Nitin Gangane ${ }^{3}$, Jaya Kore ${ }^{4}$, Neha Gangane ${ }^{5}$

${ }^{1}$ Professor, Obstetrics and Gynaecology; ${ }^{2}$ Junior Resident, Obstetrics and Gynaecology; ${ }^{3}$ Professor and Head, Pathology; ${ }^{4}$ Senior Resident, Obstetrics and Gynaecology; ${ }^{5}$ Assistant Professor, Obstetrics and Gynaecology, Mahatma Gandhi Institute of Medical Sciences, Sewagram, India.
} 